\title{
The importance of active learning elements in the design of online courses
}

\author{
Alex Koohang, Middle Georgia State University, alex.koohang@mga.edu \\ Joanna Paliszkiewicz, Warsaw University of Life Sciences, joanna_paliszkiewicz@sggw.pl \\ Deanna Klein, Minot State University, deanna.klein@minotstateu.edu \\ Jeretta Horn Nord, Oklahoma State University, jeretta.nord@okstate.edu
}

\begin{abstract}
The purpose of this study was to investigate learners' perceived views about the importance of including active learning elements in the design of online courses giving attention to three selected variables: age, gender, and college status. The subjects participated in the study were undergraduate and graduate students taking online courses at a medium-sized University in the Midwest, USA. ANOVA was used to analyze the collected data. Significant mean differences were reported for all three selected variables. Conclusion, implications, and recommendations for future research are made.
\end{abstract}

Keywords: Active learning elements, online courses, e-learning, knowledge construction

\section{Introduction}

Active learning is about engaging and involving learners in the learning process (Duch et al., 2001). In an active learning environment, learners engage in higher order thinking, i.e., analysis, synthesis, and evaluation. They are in control of their learning (Bransford, Brown \& Cocking 2003). Active learning necessitates learners to participate directly in the learning process (Ryan and Martens 1989), It also requires them to take a "dynamic and energetic role" in the learning process. (Petress, 2008, p. 566)

Meyers and Jones (1993, p. xi) defined active learning as learning that allows "students to talk and listen, read, write, and reflect as they approach course content through problem-solving exercises, informal small groups, simulations, case studies, role-playing, and other activities - all of which require students to apply what they are learning". Van Amburgh, Devlin, Kirwin, \& Qualters (2007) described active learning as learning that successfully takes place with three elements: context, engagement, and reflection. Gokhale (1995) and Brown, Freeman (2000) believed that learners develop critical thinking and create self-directed learning through active learning.

Active learning is important in helping students to become "self-regulated learners", which in turn makes them "lifelong learners". In an active learning environment, teachers can help learners to initiate learning tasks, set goals for learning, and adopt strategies for successful learning. Through active learning, students become responsible for their learning (Zimmerman, 2002). 
According to Dickinson (1993), active learning can create autonomous learners in which the learners verify what has been taught, launch learning objectives, select an appropriate learning strategy, and choose alternative effective learning strategy. In active learning, students become partners. Teachers, in contrast, are motivators and guides. Active learning helps students with the transition from dependent learning to independent learning. Individuals learn more effectively when they solve problems and discover things on their own (Leidner \& Jarvenpaa 1995). Raux and College (2004) believed that active learning stimulates independent thinking and problem solving.

Active learning in e-learning has been the focus of many studies (e.g., Chen, Lambert, \& Guidry, 2010; Donovan, 2005; Hrastinski, 2008; Huffaker, \& Calvert, 2003; Koohang, \& Paliszkiewicz, 2013; Koohang, Kohun, \& DeLorenzo, 2013; Koohang, Paliszkiewicz, Nord, \& Ramim, 2014; Koohang, Riley, Smith, \& Schreurs, 2009; Koohang, Smith, Yerby, \& Floyd, 2012; Swan, 2003). In particular, Koohang (2012) stated that knowledge construction in e-learning is accomplished through active learning elements in three main continuous stages: underpinning, ownership, and engaging.

The underpinning stage of active learning in e-learning is responsible for building the groundwork for learning. The elements in the underpinning stage are real world/relevant examples, exploration, higher-order thinking skills, and scaffolding. This stage commences the learning process and creates the foundation for knowledge construction that enforces learners to become active learners. The instructor plays a critical role in designing these elements into the learning activities.

The ownership stage follows the underpinning stage. This stage encourages learners to own their learning. It empowers learners to have confidence and take control of their learning. The elements of the ownership stage are learner's own driven goals/objectives, learner's selfmediating/control of learning, learner's self-reflection/awareness, learner's use of own experience, learner's self-assessment, and learner's representation of ideas/concepts. These elements are designed in the course activities by the instructor to guide learners to participate actively in the ownership of their learning.

The engaging stage follows the ownership stage. In the engaging stage learners' build a community of learners to actively construct new knowledge. The elements of the engaging stage are learners' active and collaborative engagement in analysis, evaluation, \& synthesis of multiple perspectives; and learners collaboratively assessing each other. These elements are designed to the course activities by the instructor who actively coaches, guides, mentors, tutors, assesses, communicates, and provides feedback to learners (Koohang 2012).

The purpose of this study was to examine learners' perceived views about the importance of including the active learning elements (twelve elements in three stages: underpinning, ownership, and engaging) in the design of online courses giving attention to three selected variables: age, gender, and college status. Consistent with the study's purpose three research questions (RQ) emerged:

- RQ \#1: Are there significant mean differences between learners' age and their perceived views about the importance of including active learning elements in online courses? 
- RQ \#2: Are there significant mean differences between learners' gender and their perceived views about the importance of including active learning elements in online courses?

- RQ \#3: Are there significant mean differences between learners' college status (undergraduate/graduate) and their perceived views about the importance of including active learning elements in online courses?

Allen \& Seaman (2007 \& 2010) reported age-related differences in relation to online courses. However, some studies have reported no significant differences between age in online learning (Yukselturk \& Bulut, 2007; Shultz, Shultz, \& Round, 2010; Koohang, Smith, Yerby, \& Floyd, 2012; Koohang, Kohun, \& DeLorenzo, 2013). In the present study, we chose age as a variable of interest to see whether the present study's population sample reveals differences between learners' age and their perceived views about the importance of including active learning elements in online courses.

Gender-related differences reports in relation to online courses and the technology, in general, have been conflicting in the literature. For example, Koohang, Kohun, \& DeLorenzo (2013), Shultz, Shultz, \& Round (2010) and Yukselturk \& Bulut (2007) reported no gender-related significant differences with online courses. However, in a study of active learning in online courses conducted by Koohang, Smith, Yerby, \& Floyd (2012), the authors found gender-related differences. Female students significantly scored lower than male students did regarding their perception of the learning experience in online courses. In the present study, we chose gender as a variable of interest to see whether the present study's population sample reveals differences between learners' gender and their perceived views about the importance of including active learning elements in online courses.

Koohang, Kohun, \& DeLorenzo (2013) found a significant difference in the levels of undergraduate students' and their perception of active learning in e-learning. Fourth-year students significantly scored higher than all other levels (first-year, second-year, and third-year students). In the present study, college status, i.e., undergraduate and graduate, was selected as a variable of interest to see whether the present study's population sample reveals differences between learners' college status and their perceived views about the importance of including active learning elements in online courses.

In the present study, knowledge construction through active learning in e-learning is treated as the dependent variable. The independent variables are age, gender (male/female) and college status (undergraduate/graduate).

\section{Method}

\section{The instrument}

The instrument for this study is based on the knowledge construction through active learning in e-learning model proposed by Koohang (2012). The model asserted that knowledge construction in e-learning is accomplished through active learning in three main continuous stages: underpinning, ownership, and engaging. Koohang and Paliszkiewicz (2013) empirically validated the model for reliability. 
The present study used the twelve elements of the knowledge construction through active learning in e-learning model to create an instrument to gather information about the subjects' opinion about the importance of inclusion of the active learning elements in their online course activities, assignments, and or projects.

The items of the instrument were as follows:

1. Higher-order thinking skills (analyzing, evaluating, \& synthesizing problems)

2. Exploration (seeking knowledge independently)

3. Real world/relevant examples (using real world and relevant examples)

4. Scaffolding (thinking above and beyond what I normally learn)

5. Self-driven goals and objectives (setting my learning goals and objectives)

6. Self-mediating/control of learning (self-mediating and being in control of my learning)

7. Self-reflection/awareness (being self-aware and self-reflect)

8. Learner's experience (including my previous experience in solving a problem)

9. Self-assessment (self-assessment of my learning)

10. Learner's representation of ideas/concepts (presenting my ideas/concepts)

11. Active engagement (actively analyzing, evaluating, \& synthesizing multiple perspectives expressed by other classmates)

12. Collaborative assessment (assessing everyone else's learning progress)

The instrument used the following scoring strategy: Very Important $=5$, Important $=4$, Moderately Important $=3$, Of Little Importance $=2$, and Unimportant $=1$.

\section{Sample Population \& Procedure}

After obtaining approval from the University's Institutional Research Board where this study took place, the instrument was distributed electronically to over 200 students who were taking online courses in both undergraduate and graduate programs at a University in the Midwest, USA. Over a one-month period, 160 responses were collected. Of the 160 responses, 15 were eliminated because of incomplete data, yielding 145 completed questionnaires. The outlier analysis further eliminated three subjects from the dataset. This resulted in 142 total subjects used in the present study. The 142 subjects were from various age groups. They were males and females enrolled in both undergraduate and graduate online courses. The undergraduate subjects were studying in the field of Information Systems. The graduate subjects were studying in the Management field. The age of the subjects was as follows: $18-23(33.1 \%), 24-29(22.5 \%), 30$ - 35 (16.9\%), $36-41(11.3 \%)$, and over $41(16.2 \%)$. The subjects were males $(45.1 \%)$ and females $(54.9 \%)$. The subjects were both undergraduate $(58.5 \%)$ and graduate students $(41.5 \%)$. The subjects were assured confidentiality and anonymity. All subjects were over 18 years of age. Their participation in the study was voluntary.

\section{Data analysis}

Research questions were answered by conducting three separate one-way analysis of variance (ANOVA). The ANOVA test was conducted because it reveals the significance of group differences. ANOVA test presents the effect of one independent variable on one dependent variable. The ANOVA procedure requires the following: 1) the dependent variable must be 
continuous; 2) the independent variables must consist of two or more independent groups/levels; 3) no relationship must be established between the observations in each group or between the groups; and 4) the outliers must be eliminated from the data set (Mertler and Vannatta, 2010). Once these requirements are fulfilled, the data are tested for homogeneity of variances for each independent variable. Levene's test of homogeneity of variances is used to find out whether samples have equal variances. If $p$ is greater than .05 , there is equality of variances among sample population. If $p$ is less than .05 , the test of homogeneity of variances fails and Welch ANOVA must be used. Next, the F statistic in the ANOVA test establishes the significance of the groups. If an independent variable had more than two levels, post hoc comparison tests were conducted. Lastly, descriptive analysis was performed to show the means and standard deviation of each dependent variable with the independent variable.

\section{Results}

\section{Descriptive Analysis}

Figure 1 shows the descriptive analysis for all twelve elements of active learning. All elements of active learning received above average to high mean scores indicating learners' favorable view of the importance of the active learning elements in the design of online courses.

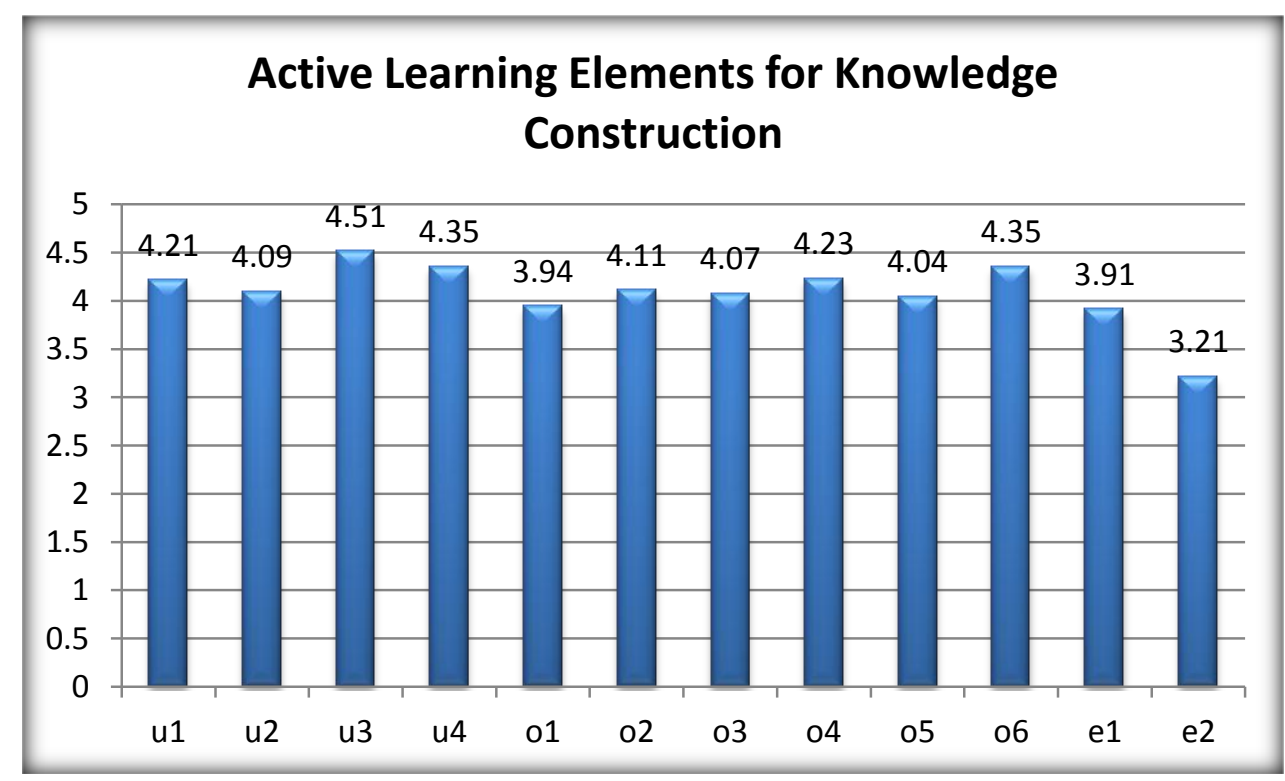

Figure 1. Descriptive Analysis

u1. Higher-order thinking skills, u2. Exploration, u3. Real world/relevant examples, u4. Scaffolding, o1.

Self-driven goals and objectives, o2. Self-mediating/control of learning, o3. Self-reflection/awareness, o4. Learner's experience, o5. Self-assessment, o6. Learner's representation of ideas/concepts, e1. Active engagement, e2. Collaborative assessment

Research Question \#1: Are there significant mean differences between learners' age and their perceived views about the importance of including active learning elements in online courses?

Step1: The following conditions for RQ\#1 were met: 
- The dependent variable (active learning in e-learning) was continuous.

- Age as an independent variable consisted of four groups/levels.

- There was no relationship established between the observations in each group/levels or between the groups/levels.

Step 2: Before testing the ANOVA, the following analyses were made:

- The outlier test was conducted before testing for homogeneity of variances among the sample population. Three (3) outliers were eliminated from the dataset.

- Levene's test of homogeneity of variances was then conducted for the variable of age to confirm the existence of equality of variances among sample population. The results (Levene Statistics $=1.758, p=.141$ ) indicating that variances are highly equivalent among the groups, and ANOVA can be conducted to test the significance of groups.

Step 3: The ANOVA

The result of the ANOVA indicated a significant difference between the independent variable of age and the dependent variables of active learning in e-learning $\left(\mathrm{F}_{4,137}=5.249, \mathrm{p}=.001\right)$. Post hoc analysis was then conducted because age included more than two levels (groups). The significant groups were $1-2(-.35960 *, p=.050), 1-3,\left(-.50717^{*}, p=.004\right)$. The descriptive analysis that includes means and standard deviation for the independent variable of age and the dependent variables of active learning in e-learning are shown in Table 1.

Table 1. Descriptives for Age

\begin{tabular}{|l|r|r|r|}
\hline Age & N & Mean & $\begin{array}{c}\text { Std. } \\
\text { Deviation }\end{array}$ \\
\hline $1=18-23$ & 47 & 3.8227 & .42478 \\
\hline $2=24-29$ & 32 & 4.1823 & .51780 \\
\hline $3=30-35$ & 24 & 4.3299 & .57288 \\
\hline $4=36-41$ & 16 & 4.1354 & .60772 \\
\hline $5=$ Over 41 & 23 & 4.1957 & .47047 \\
\hline Total & 142 & 4.0851 & .53174 \\
\hline
\end{tabular}

Research Question \#2: Are there significant mean differences between learners' gender and their perceived views about the importance of including active learning elements in online courses?

Step1: The following conditions for RQ \#2 were met:

- The dependent variable (active learning in e-learning) was continuous.

- Gender as an independent variable consisted of two groups/levels.

- There was no relationship established between the observations in each group/levels or between the groups/levels.

Step 2: Before testing the ANOVA, the following analyses were made:

- The outlier test was conducted before testing for homogeneity of variances among the sample population. Three (3) outliers were eliminated from the dataset. 
- Levene's test of homogeneity of variances was conducted for the variable of gender to confirm the existence of equality of variances among sample population. The results (Levene Statistics $=.109, p=.742$ ) indicating that variances are highly equivalent between the groups, and ANOVA can be conducted to test the significance of groups.

Step 3: The ANOVA

The result of the ANOVA indicated a significant difference between the independent variable of gender and the dependent variables of active learning in e-learning $\left(\mathrm{F}_{1,140}=17.473, p=.000\right)$. Male subjects significantly scored higher than female subjects did in their perceived views about the inclusion of active learning elements in the design of online courses. The descriptive analysis that includes means and standard deviation for the independent variable of gender and the dependent variables of active learning in e-learning are shown in Table 2.

Table 2. Descriptives for Gender

\begin{tabular}{|l|r|r|r|}
\hline Gender & \multicolumn{1}{|c|}{$\mathrm{N}$} & Mean & $\begin{array}{c}\text { Std. } \\
\text { Deviation }\end{array}$ \\
\hline $1=$ Male & 64 & 4.2799 & .51271 \\
\hline $2=$ Female & 78 & 3.9252 & .49521 \\
\hline Total & 142 & 4.0851 & .53174 \\
\hline
\end{tabular}

Research Question \#3: Are there significant mean differences between learners' college status (undergraduate/graduate) and their perceived views about the importance of including active learning elements in online courses?

Step1: The following conditions for RQ \#3 were met:

- The dependent variable (active learning in e-learning) was continuous.

- College Status as an independent variable consisted of two groups/levels.

- There was no relationship established between the observations in each group/levels or between the groups/levels.

Step 2: Before testing the ANOVA, the following analyses were made:

- The outlier test was conducted before testing for homogeneity of variances among the sample population. Three (3) outliers were eliminated from the dataset.

- Levene's test of homogeneity of variances was conducted for the variable of college status to confirm the existence of equality of variances among sample population. The results (Levene Statistics $=1.591, p=.209$ ) indicating that variances are highly equivalent between the groups, and ANOVA can be conducted to test the significance of groups.

Step 3: The ANOVA

The result of the ANOVA indicated a significant difference between the independent variable of college status and the dependent variables of active learning in e-learning $\left(\mathrm{F}_{1,140}=23.848, p\right.$ $=.000)$. Graduate subjects significantly scored higher than undergraduate subjects did in their perceived views about the inclusion of active learning elements in the design of online courses. The descriptive analysis that includes means and standard deviation for the independent variable 
of college status and the dependent variables of active learning in e-learning are shown in Table 3 .

Table 3. Descriptives for College Status

\begin{tabular}{|l|r|r|r|}
\hline College Status & N & Mean & $\begin{array}{c}\text { Std. } \\
\text { Deviation }\end{array}$ \\
\hline 1 = Undergraduate & 83 & 3.9147 & .47068 \\
\hline 5 = Gradate & 59 & 4.3249 & .52356 \\
\hline Total & 142 & 4.0851 & .53174 \\
\hline
\end{tabular}

\section{Conclusion}

This study was undertaken to examine learners' perceived views about the importance of including active learning elements (twelve elements in three stages: underpinning, ownership, and engaging) in the design of online courses. Age, gender, and college status were the variables of interest. The research questions endeavored to find out whether there were significant mean differences between learners' age, gender, and college status and their perceived views about the importance of including active learning elements in the design of online courses.

Age: The ANOVA test indicated a significant group difference between the independent variable of age and the dependent variables of active learning in e-learning. Younger learners (18 - 23) scored the lowest in the group. Learners between the ages of 30 - 35 scored significantly higher than other groups. This result is in line with research reported by Allen \& Seaman (2007 \& 2010) in which age-related differences were reported with students taking online courses in general. However, the result is in conflict with other studies where no age-related differences were found with subjects taking online courses where active learning was enforced (Yukselturk \& Bulut, 2007; Shultz, Shultz, \& Round, 2010; Koohang, Smith, Yerby, \& Floyd, 2012; Koohang, Kohun, \& DeLorenzo, 2013).

Gender: The ANOVA test indicated a significant group difference between the independent variable of gender and the dependent variables of active learning in e-learning. Male students scored significantly higher than female students did in their perceived views about the inclusion of active learning elements in online courses. This result is consistent with research conducted by Koohang, Smith, Yerby, \& Floyd (2012). However, it conflicts the previous research led by Koohang, Kohun, \& DeLorenzo (2013), Shultz, Shultz, \& Round (2010) and Yukselturk \& Bulut (2007).

College Status: The ANOVA test indicated a significant group difference between the independent variable of college status and the dependent variables of active learning in elearning. Graduate students scored significantly higher than undergraduate subjects did in their perceived views about the inclusion of active learning elements in online courses.

To reiterate, all elements of active learning received above average to high mean scores indicating learners' favorable view of the importance of the active learning elements in the design of online courses. The result is clearly a strong endorsement for the inclusion of the presented active learning elements in the development of online courses. What are the implications of this based on differences in age, gender, and college status? Students ranging in age from 30-35 
scored significantly higher than other age groups. Furthermore, graduate students scored significantly higher than undergraduate students did. These findings may suggest that mature students are likely to place a higher value on active learning elements in online courses. This finding is an indication that students with more experience may understand and value the active learning elements incorporated in online classes although all age groups including undergraduate students find these elements beneficial in the learning process. Analysis of the independent variable, gender, revealed that male students scored significantly higher than female students did in their perceived views about the inclusion of active learning elements in online courses. This finding was consistent with one previous study reviewed, yet inconsistent with three studies previously conducted. The implication is that results by gender may continue to vary based on the target population. However, both genders' scores revealed favorable views of active learning elements in online courses. Based on this, instructors may find it helpful to have a mix of males and females for group activities in online courses.

This research revealed learners' perceived views about the importance of including active learning elements in the design of online courses by age, gender, and college status. Are perceived views an indication of actual learning? Future research would be beneficial to study actual learning based on a comparison of a group of learners taking online courses with active learning elements incorporated in the courses and a group of learners taking online courses without the described active learning elements.

Limitations of the study are the size of the target population and limited geographic location. Future studies should include an increased number of participants from various geographic areas to improve the generalizability of the research.

\section{References}

Allen, E. \& Seaman, J. (2007). Online nation: Five Years of Growth in Online Learning. The Sloan Consortium. Retrieved January 10, 2016 from http://www.onlinelearningsurvey.com/reports/online-nation.pdf

Allen, E., \& Seaman, J. (2010). Class differences: Online education in the United States. The Sloan Consortium. Retrieved January 10, 2016 from http://www.onlinelearningsurvey.com/reports/class-differences.pdf

Bransford, J., Brown, A., \& Cocking, R. (Eds.). (2003). How people learn: Brain, mind, experience, and school. Washington, DC: National Academy Press.

Brown, M. N., \& Freeman, K. (2000). Distinguishing features of critical thinking classrooms. Teaching in Higher Education, 5(3), 301-309.

Chen, P., Lambert, A., \& Guidry, K. (2010). Engaging online learners: The impact of Webbased learning technology on college student engagement. Computers \& Education, 54(4), 1222-1232.

Dickinson, L. (1993). Talking shop: Aspects of autonomous learning. ELT Journal, 47(4), 330336. 
Donovan, J. (2005). Active Learning in Online Classes. In G. Richards (Ed.), Proceedings of ELearn: World Conference on E-Learning in Corporate, Government, Healthcare, and Higher Education 2005 (pp. 1280-1284). Chesapeake, VA: Association for the Advancement of Computing in Education (AACE).

Duch, B., Groh, S., \& Allen, D. (2001). The Power of Problem - Based Learning. Stylus Publishing, LLC, Sterling, Virginia.

Gokhale, A. (1995). Collaborative learning enhances critical thinking. Journal of Technology Education, 7(1), 2-30.

Hrastinski, S. (2008). What is online learner participation? A literature review. Computers \& Education, 51(4), 1755-1765.

Huffaker, D. \& Calvert, S. (2003). The new science of learning: Active learning, metacognition, and transfer of knowledge in e-learning applications. Journal of Educational Computing Research, 29(3), 325-334.

Koohang, A. \& Paliszkiewicz, J. (2013). Knowledge construction in e-learning: An empirical validation of an active learning model. The Journal of Computer Information Systems, 53(3), 109-114.

Koohang, A. (2012). Active learning in e-learning: advancing a systemic model. Issues in Information Systems, 13(1), 68-76.

Koohang, A., Kohun, F., \& DeLorenzo, G. (2013). Knowledge construction through active learning in e-Learning: An empirical study. The Online Journal of Applied Knowledge Management, 1(1), 18-28.

Koohang, A., Paliszkiewicz, J., Nord, J., \& Ramim, M. (2014). Advancing a theoretical model for knowledge construction in e-learning. The Online Journal of Applied Knowledge Management, 2(2), 12-25.

Koohang, A., Riley, L., Smith, T. \& Schreurs, J. (2009). E-Learning and Constructivism: From Theory to Application. Interdisciplinary Journal of E-Learning \& Learning Objects, 5(1), 91-109.

Koohang, A., Smith, T., Yerby, J., \& Floyd, K. (2012). Active learning in online courses: an examination of students' learning experience. International Journal of Management, Knowledge and Learning, 1(2), 205-216.

Leidner, D. E., \& Jarvenpaa, S. L. (1995). The use of information technology to enhance management school education: a theoretical view. MIS Quarterly, 19(3), 265-291.

Mertler, C.A., \& Vannatta, R.A. (2010). Advanced and multivariate statistical methods. Los Angeles, CA: Pyrczak.

Meyers, C., Jones, T. B. (1993). Promoting Active Learning. Strategies for the College Classroom. Jossey-Bass, San Francisco.

Petress, K. (2008). What is meant by active learning? Education, 128(4), 566-569.

Raux, D. J., College, S. (2004). Implementing active learning in college. Explorations in 
Teaching and Learning, 2(1), 2-4.

Ryan, M. P., \& Martens, G. G. (1989). Planning a college course: A guidebook for the graduate teaching assistant. Ann Arbor, MI: The National Center for Research to Improve Postsecondary Teaching and Learning, The University of Michigan.

Schultz, M. C., Schultz, J. T., \& Round, E. (2010). The effects of chronological age on management and business administration student performance in online/distance education courses. The Business Review, 16(1), 245-251.

Swan, K. (2003). Learning effectiveness online: What the research tells us. Elements of quality online education, practice and direction, 4, 13-47.

Van Amburgh, J. A., Devlin, J. W., Kirwin, J. L., \& Qualters, D. M. (2007). A Tool for Measuring Active Learning in the Classroom. American Journal of Pharmaceutical Education, 71(5) Article 85, 1-9.

Yukselturk, E., \& Bulut, S. (2007). Predictors for student success in an online course. Educational Technology \& Society, 10(2), 71-83.

Zimmerman, B. J. (2002). Becoming a self-regulated learner: An overview. Theory Into Practice, 41(2), 64-70.

\section{Authors' Biographies}

Alex Koohang is Professor and Dean in the School of Information Technology at Middle Georgia University. He has published and presented numerous papers. Currently, he is the editorin-chief of the Journal of Computer Information Systems and serves on the editorial review board of several IS/MIS publications. Dr. Koohang is the Peyton Anderson Eminent Scholar and Endowed Chair in Information Technology and was awarded the 2009 Computer Educator of the Year by IACIS.

Joanna Paliszkiewicz is a specialist in management issues connected with knowledge management, intellectual capital, and trust management. She holds the rank of University Professor of Warsaw University of Life Sciences and Polish-Japanese Academy of Information Technology. Prof. J. Paliszkiewicz is well recognized in Poland and abroad with her expertise in management issues. She has published over 145 original papers and 3 books. She serves on the editorial board of several international journals. She is the deputy editor-in-chief of Management and Production Engineering Review Journal. Prof. J. Paliszkiewicz has been awarded a number of grants sponsored by Polish Ministry of Sciences. In recognition of her outstanding teaching and research, Professor J. Paliszkiewicz has been the recipient of the three awards of excellence from the Rector of the Warsaw University of Life Sciences. Dr. Paliszkiewicz was named the 2013 Computer Educator of the Year by IACIS.

Deanna Klein is a Professor in the College of Business, Department of Business Information Technology. Deanna teaches undergraduate and graduate classes in the area of systems analysis and design, project management and Projects in MIS. She is a professional member of the International Association for Computer Information Systems (IACIS), and Informing Science 
Institute (ISI), is currently International Assembly for Collegiate Business Education (IACBE) Region 5 Past President, as well as a member and Past President of Delta Kappa Gamma Gamma Chapter.

Jeretta Horn Nord is Professor of Management Information Systems at Oklahoma State University. She has recently served as Visiting Scholar at the University of California at Los Angeles and as a Visiting Professor at the University of Southern Queensland in Australia; she has also been named Computer Educator of the Year by IACIS. Dr. Nord has authored numerous articles, proceedings, conference papers, and books in the areas of e-business, corporate knowledge requirements, and entrepreneurship. Jeretta has presented papers in over 20 countries and serves as Director of Publications to the IACIS Executive Board and Executive Editor of The Journal of Computer Information Systems. She holds the Jeanine Rhea/Oklahoma International Women's Forum Professorship and was recently named among the top 20 women professors in Oklahoma. 